\title{
Androgenic control of immunoreactive somatostatin in the Harderian gland of the Syrian hamster*
}

\author{
M. Puig-Domingo, J. M. Guerrero, R. J. Reiter, M. A. Peinado†, \\ A. Menendez-Pelaez, C. Santana and S. M. Webb $\dagger$ \\ Department of Cellular and Structural Biology, The University of Texas Health Science Center at \\ San Antonio, 7703 Floyd Curl Drive, San Antonio, TX 78284, U.S.A. and \\ $\dagger$ †epartment of Endocrinology, Hospital de Sant Pau, Universitat Autonoma de Barcelona, \\ Av. San Antonio M. Claret 167, Barcelona 08025, Spain
}

\begin{abstract}
Summary. Harderian glands of Syrian hamsters contained measurable levels of immunoreactive somatostatin. After an extraction procedure, serial dilutions of tissue were assayed and showed parallelism in the displacement curve with dilutions of purified somatostatin standard in the radioimmunoassay. Somatostatin concentrations were higher in female hamsters $(10.0 \pm 2.1 \mathrm{ng} / \mathrm{mg}$ protein) than in males $(2.6 \pm 0.4 \mathrm{ng} / \mathrm{mg}$ protein). Castrated males had somatostatin values in the range of females $(12.4 \pm 2 \cdot 3 \mathrm{ng} /$ mg protein) at 1 month after gonadectomy. Testosterone implants prevented the rise of Harderian gland somatostatin in castrated males. Gonadectomized males had lower somatostatin content in the gland than did control males $(1 \cdot 0 \pm 0.2 \mathrm{ng} / \mathrm{mg}$ protein) at 2 months after castration. Somatostatin values in females were unaffected by gonadectomy, but there were variations during the oestrous cycle, with a nadir dectected at dioestrus-1 and maximal values coincident with the day of the ovulation.
\end{abstract}

Keywords: somatostatin; Harderian gland; androgens; Syrian hamster

\section{Introduction}

Somatostatin has a widespread distribution in the body of vertebrates. Since the first report (Brazeau et al., 1973) of its presence in the tubero-infundibular system, it has been found in many other sites in the nervous system including the neurohypophysis (Patel et al., 1979), limbic system, cortex and hippocampus (Krisch, 1978), pineal gland (Webb et al., 1984), and in several classes of sensory neurones, e.g. retina and auditory system (Hokfelt et al., 1980). Outside the nervous system somatostatin is present in secretory cells of the gut and pancreatic islets (Polak et al., 1975), the salivary glands (Molnar et al., 1976), the urinary system (Bolaffi et al., 1980), the parafollicular cells of the thyroid (Van Noorden et al., 1977) and in the amniotic fluid (Fitzpatrick \& Patel, 1979). It has been classified into different physiological categories: a neurohormone or a neurotransmitter in the nervous system, a paracrine factor in the pancreas, a true hormone in some cases with effects on different target organs, and a lumone with regulatory actions when secreted in the lumen of the gut (see review by Reichlin, 1983).

In this paper we report the presence of immunoreactive somatostatin in the Harderian gland of the Syrian hamster, a tubulo-alveolar gland located in the posterior aspect of the orbit; this gland shows a remarkable sexual dimorphism in the hamster in terms of porphyrin and melatonin content, and cellularity (Hoffman, 1971; Hoffman et al., 1985). 


\section{Materials and Methods}

Young adult male and female Syrian hamsters weighing 100-125 g were purchased from Sasco (Omaha, NE, U.S.A.) and housed 8 per cage under a $14 \mathrm{~h}$ light: $10 \mathrm{~h}$ dark lighting regimen (lights on at 06:00 h) in a room with a controlled temperature of $23 \pm 2^{\circ} \mathrm{C}$; they were provided with food and tap water ad libitum.

Experiment 1. Male hamsters $(\mathrm{N}=6)$ were killed by decapitation and the Harderian glands were quickly removed, weighed, placed in vials containing $750 \mu l 0.5 \mathrm{~N}$ cold acetic acid, frozen on solid $\mathrm{CO}_{2}$ and stored at $-70^{\circ} \mathrm{C}$ until assayed. These glands were used for a displacement curve assay with serial dilutions of the tissue previously extracted against synthetic $\left[\mathrm{Tyr}^{1}\right]$ somatostatin standard obtained from Bachem Inc. (Torrance, CA, U.S.A.). Before the assay, samples were rapidly thawed, the vials containing the Harderian gland placed in boiling water for 5 min, and then transferred to a cold bath $\left(4^{\circ} \mathrm{C}\right)$ where the remainder of the procedures were carried out. After homogenization $(80 \mathrm{mg}$ tissue $/ \mathrm{ml} 0.5 \mathrm{~N}$-acetic acid) using a Polytron (Kynematica, Lucerne, Switzerland), aliquants of $50 \mu 1$ for total protein assay by the method of Lowry et al. (1951) were collected. To the aliquants, $250 \mu 1$ cold $0.01 \mathrm{M}-\mathrm{PBS} 0.01 \%$ BSA $\mathrm{pH} 7.4$ were added; debris was removed by 30 min centrifugation at $1500 \mathrm{~g}$; the supernatant was serially diluted with $0.05 \mathrm{M}$-PBS, $\mathrm{pH} 7 \cdot 4$, containing $0.025 \mathrm{M}$-EDTA, $0.1 \%$ Triton X-100 and $0.5 \%$ BSA. Immunoreactive somatostatin was determined by radioimmunoassay using the antibody R101 (Arimura et al., 1975), raised in rabbit against cyclic somatostatin at a final dilution of 1:25000. Synthetic [Tyr ${ }^{1}$ ]somatostatin, labelled with ${ }^{125}$ I from Amersham (Arlington Heights, IL, U.S.A.) by the chloramine-T method and purified on an octadecasilyl-silica column, was used as the tracer. The bound and free hormones were separated by dextran-coated charcoal. The detection limit in our assay was $2 \mathrm{pg} /$ tube. The intra-assay coefficient of variation was $10 \%$ for samples containing around $30 \mathrm{pg}$ somatostatin/tube and $13 \%$ for values around $120 \mathrm{pg} /$ tube; the coefficient of variation between assays was $15 \%$ for values around $30 \mathrm{pg} /$ tube. Results were corrected by the percentage of extraction recovery determined by the addition of tracer to the homogenates (c.p.m. recovered in the supernatant divided by total c.p.m. added and multiplied by $100)$; this ranged between 66 and $69 \%$. Results were also corrected by the non-specific binding value obtained for each dilution, which was different from that obtained in the standard curve. As an additional check on assay specificity, pieces of preheated hamster Harderian gland $\left(80^{\circ} \mathrm{C}\right.$ for $\left.40 \mathrm{~min}\right)$ were subjected to the extraction procedure and assayed for immunoreactive somatostatin to determine a tissue blank effect.

Experiment 2. The effect of gonadectomy on the somatostatin content of the Harderian gland was studied; male and female hamsters were bilaterally gonadectomized while under ether anaesthesia. At 30 days after operation the glands were collected at 13:00 h from gonadectomized and intact control animals ( 8 animals in each group) for determination of immunoreative somatostatin.

Experiment 3. The time course of the changes in immunoreactive somatostatin in Harderian glands of castrated males was studied in this experiment; adult male hamsters were castrated ( 8 per group) and their Harderian glands were collected at 30 and 60 days after surgery.

Experiment 4. Hamsters were castrated and 15 days later 8 of the 16 males received a subcutaneous implant of testosterone propionate (Sigma, St Louis, MO, U.S.A.; $10 \mathrm{mg}$ in $20 \mathrm{mg}$ beeswax). After another 15 days castrated hamsters with and without the testosterone implant and 8 untreated controls were killed at 13:00 h. Harderian glands were collected and processed as in Exp. 1. Plasma testosterone concentration was measured using a commercial kit from Diagnostic Products (Los Angeles, CA, U.S.A.). The sensitivity of this radioimmunoassay is $0.2 \mathrm{ng} / \mathrm{ml}$ and the cross-reactivity with dihydrotestosterone is less than $10 \%$.

Experiment 5. To study the concentrations of immunoreactive somatostatin in Harderian glands of female hamsters throughout the oestrous cycle, 35 adult females were checked daily for post-ovulatory vaginal discharge (Orsini, 1961). After 3 complete 4-day cycles animals were killed at 13:00 h for collection of Harderian glands and assay of somatostatin ( $\mathrm{N}=7-8$ in each group).

Statistics. Data were analysed using the Student-Newman-Keuls test.

\section{Results}

\section{Experiment 1}

The specificity of the extraction and assay procedure were checked by assaying serial dilutions of tissue extract and comparing them to purified standard somatostatin; as shown in Fig. 1 the tissue dilution curve paralleled the standard dilution, as indicated by the fact that slopes were not significantly different $(P>0.05)$. The preheated Harderian gland extract had no detectable somatostatin activity which indicated that the extraction procedure and the resulting extract alone did not displace somatostatin from its antiserum. 


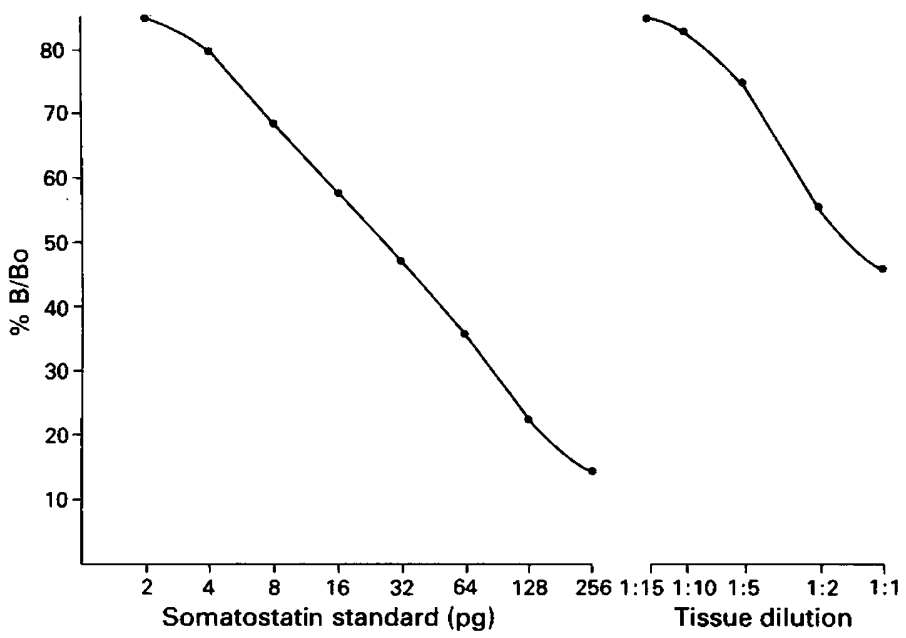

Fig. 1. Displacement curves for serial dilution of somatostatin standard and Harderian gland extract. Tissue extracts were derived from 6 male hamsters. The mean of 3 replicates for each Harderian gland and 3 replicates of standard [ $\mathrm{Tyr}^{1}$ ] somatostatin are plotted as the log concentration or dilution versus the percentage of the c.p.m. that were bound to antiserum R101 in the absence of somatostatin standard or Harderian gland extract $(\% B)$. The slopes of the dilution curves are not significantly different.

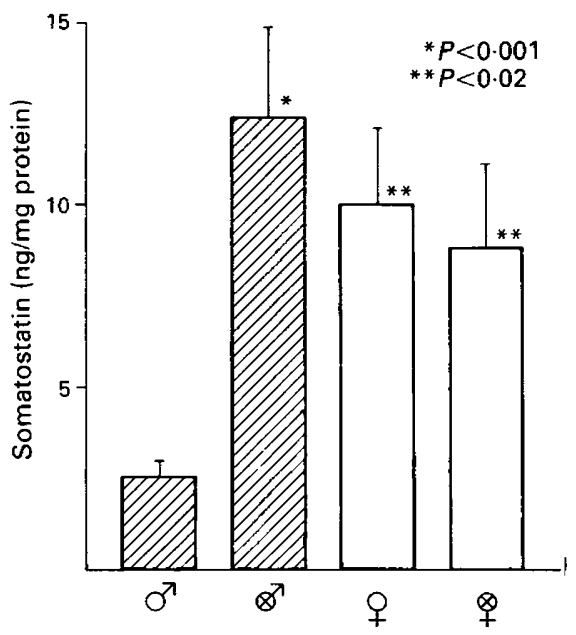

Fig. 2. Concentrations of Harderian gland somatostatin in intact and gonadectomized (1 month) male and female hamsters. Values are mean \pm s.e.m. for 8 hamsters/group.

\section{Experiment 2}

Control females had higher $(P<0.02)$ amounts of immunoreactive somatostatin than did males (Fig. 2). Castrated males, when studied 30 days after gonadectomy, showed a 4-fold $(P<0.001)$ increase in somatostatin content (Fig. 2) when compared to male controls. Gonadectomy for 30 days did not affect significantly Harderian gland somatostatin content in females (Fig. 2). 
(a)

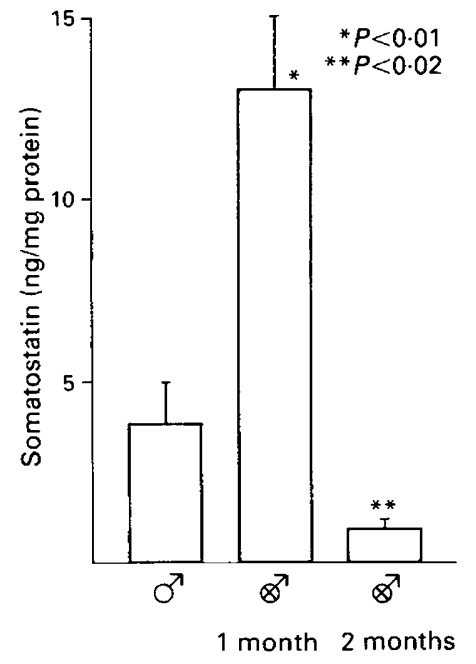

(b)

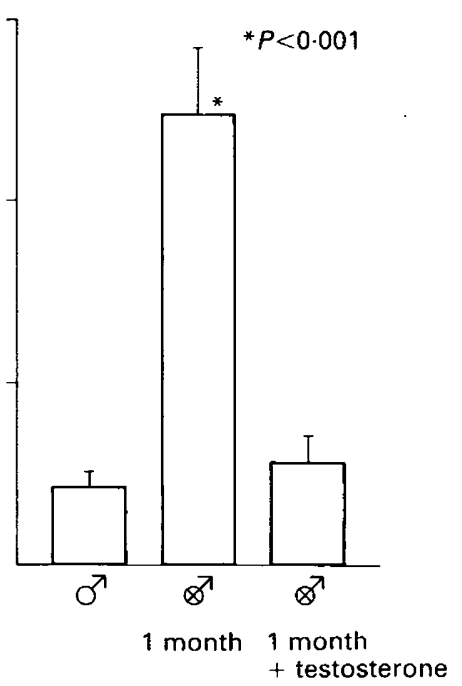

Fig. 3. Harderian gland somatostatin concentrations in castrated male hamsters at 1 and 2 months after gonadectomy (a) and effect of testosterone treatment of 1-month castrated males. Values are mean \pm s.e.m. for 8 hamsters/group.

\section{Experiment 3}

At 30 days after castration there was a 3 -4-fold increase $(P<0.01)$ in the somatostatin content of the Harderian glands compared with intact controls (Fig. 3a). However, at 2 months after gonadectomy, values were very much lower $(P<0.02)$ (Fig. 3a).

\section{Experiment 4}

The testosterone implant prevented the rise of somatostatin in the Harderian gland normally associated with gonadectomy (Fig. 3b). The ability of testosterone to prevent the rise of somatostatin in the Harderian gland was obvious even though, at 2 weeks after pellet implantation, plasma testosterone had fallen to $10 \%$ of normal concentrations.

\section{Experiment 5}

As shown in Fig. 4, highest values of somatostatin in the Harderian glands of females were reached on the day of the ovulation, i.e. oestrus, and the lowest values were found at dioestrus-1 $(P<0.01$ when compared with the values at oestrus). After dioestrus-1, there was a progressive increase in the Harderian gland somatostatin content during dioestrus- 2 and pro-oestrus.

\section{Discussion}

We report here, for the first time, the existence of immunoreactive somatostatin in the Harderian gland of the Syrian hamster. As indicated by the parallelism of the displacement curves, our results strongly suggest that the methodology used reliably measured immunoreactive somatostatin. Antiserum R101 is known to recognize the 5-13 amino acid residues which correspond to the biologically active part of the somatostatin molecule (Arimura et al., 1978). From these studies, it is not possible to conclude which form of somatostatin, i.e. a molecule with 14, 28 or more amino 


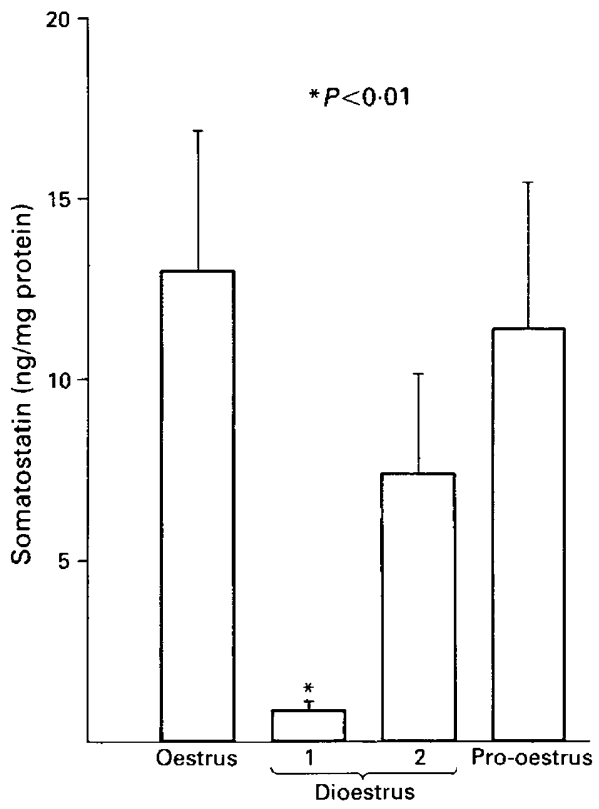

Fig. 4. Somatostatin concentration in the Harderian gland of female hamsters studied throughout the oestrous cycle. Levels were maximal at the day of oestrus and minimal at the 1st day of dioestrus. Values are mean \pm s.e.m. for $7-8$ hamsters/group.

acid residues, is predominant in the hamster Harderian gland. However, the high degree of parallelism observed in the displacement curve assay suggests that the molecular form measured might be the somatostatin-14, although no definitive statement can be made until studies by high-pressure liquid chromatography have been conducted. Contamination of the Harderian gland tissue by plasma somatostatin is unlikely. Despite the lack of availability of data on circulating concentrations of somatostatin levels in hamsters, in other species (man: Webb et al., 1985; rat: Arimura et al., 1978) plasma values are $\sim 100 \mathrm{pg} / \mathrm{ml}$. The concentrations of somatostatin found in the Harderian gland, which are at least 10-15 times higher, would therefore be unlikely to be due exclusively to haematological contamination. The Harderian gland, which contains melatonin (Hoffman et al., 1985; Menendez-Pelaez et al., 1987a), has immunoreactive somatostatin concentrations which are in the same range as those reported for the pineal gland (Webb et al., 1985), the main source of melatonin.

We also report herein the existence of sexual differences in the Harderian gland somatostatin content with values being 3 -fold higher in females than in males. Porphyrins and melatonin, both non-peptides, also exhibit sexual differences in the hamster Harderian gland (Hoffman, 1971; Hoffman et al., 1985), and androgens determine these differences. The marked rise of somatostatin activity in Harderian glands of males after castration, with no effect of gonadectomy in the females, strongly suggests an androgenic control of Harderian gland somatostatin content in the hamster. This is further supported by the fact that a subcutaneous implant of testosterone prevented the striking increase in somatostatin of the gland after castration. The fact that inhibition of the rise occurred even though the circulating testosterone was $10 \%$ of the normal level suggests a supersensitivity of Harderian somatostatin to androgen. Specific androgen receptors in the Harderian gland of the male hamster have been described (Vilchis et al., 1987).

The transitory nature of the rise in somatostatin with a return to values below those for intact male at 2 months after castration remains unexplained. However, a recovery to ultrastructure 
typical of normal males has been reported for Harderian glands of males gonadectomized 4 months earlier (Menendez-Pelaez et al., 1987b).

No changes in the somatostatin content of the Harderian gland were evident after ovariectomy; this is similiar to other studies that have shown no effect of the loss of the ovaries on morphology, melatonin content or porphyrin content of the gland. Likewise, treatment of male hamsters with oestradiol does not affect these measures (Hoffman, 1971; Clabough \& Norvell, 1973). When Harderian gland somatostatin content was studied throughout the oestrous cycle, a marked drop in content was observed during the 1st day of dioestrus. There is a similarity between changes in plasma concentrations of oestradiol, progesterone and luteinizing hormone (Lisk, 1985) and somatostatin in the Harderian gland in that values of each peak just before or at the time of oestrus and are lowest at dioestrus-1. However, ovariectomy had no effect on Harderian gland somatostatin, suggesting that ovarian-derived hormones have little to do with the content of the peptide in the gland. A possible relationship between the pituitary and the Harderian gland needs further study in hypophysectomized female hamsters. There is a decline in immunoreactive somatostatin in different hypothalamic nuclei of the rat during pro-oestrus (Knuth et al., 1983), and the Harderian gland of the female hamster shows fluctuations in porphyrin content during the oestrous cycle (Moore et al., 1977), which suggests that, along with a potent androgenic control, other currently unknown factors may modulate the Harderian gland activity when androgens are absent.

This work was supported by a Spanish-US Joint Committee grant no. 83/106 (M.P.-D., R.J.R., M.A.P. and S.M.W.); J.M.G. was supported by a fellowship from the Fulbright Commission. A.M.-P. was supported by a fellowship from the Regional Government of Asturias (Spain) and C.S. by a fellowship of the Regional Government of Canary Islands (Spain).

\section{References}

Arimura, A., Sato, H., Coy, D.H. \& Schally, A.V. (1975) Radioimmunoassay for GH-release inhibiting hormone. Proc. Soc. exp. Biol. Med. 148, 784-789.

Arimura, A., Lundvquist, G., Rothman, J., Chang, R., Fernandez-Durango, R., Elde, R., Coy, D.H., Meyers, C. \& Schally, A.V. (1978) Radioimmunoassay of somatostatin. Metabolism 27, Suppl. 1, 1139-1 144

Bolaffi, J.L., Reichlin, S., Goodman, D.B.P. \& Forrest, J.N. (1980) Somatostatin: Occurrence in urinary bladder epithelium and renal tubules of the toad, Bufo marinus. Science, N.Y. 210, 644-646.

Brazeau, P., Vale, W., Burgus, R., Ling, N., Butcher, M., Rivier, J. \& Guillemin, R. (1973) Hypothalamic polypeptide that inhibits the secretion of immunoreactive pituitary growth hormone. Science, N.Y. 179, 77-79.

Clabough, J.W. \& Norvell, J.E. (1973) Effects of castration, blinding and the pineal gland on the Harderian glands of the male golden hamster. Neuroendocrinology 12, 344-353.

Fitzpatrick,D. \& Patel, Y.C. (1979) Measurement, characterization and source of somatostatin-like immunoreactivity in human amniotic fluid. J. clin. Invest. 64, $737-742$.

Hofiman, R.A. (1971) Influence of some endocrine glands, hormones and blinding on the histology and porphyrins of the Harderian glands of golden hamsters. Am. J. Anat. 132, 463-478.

Hoffman, R.A., Johnson, L.B. \& Reiter, R.J. (1985) Harderian glands of golden hamsters: temporal and sexual differences in immunoreactive melatonin. $J$. Pineal Res. 2, 161-168.

Hokfelt, T., Johanson, O., Ljungdahl, A., Lundberg, J.M. \& Schultzberg, M. (1980) Peptidergic neurons. Nature, Lond. 284, 512-521.

Knuth, U.A., Sikand, G.S., Casanueva, F.F. \& Friesen, H.G. (1983) Changes in somatostatin-like activity in discrete areas of the rat hypothalamus during different stages of proestrus and diestrus and their relation to serum gonadotropin, prolactin and growth hormone levels. Endocrinology 112, 1506-1511.

Krisch, B. (1978) Hypothalamic and extrahypothalamic distribution of somatostatin-immunoreactive elements in the rat brain. Cell Tiss. Res. 195, 499-513

Lisk, R.D. (1985) The estrous cycle. In The Hamster. Reproduction and Behavior, pp. 23-51. Ed. H. I. Siegel. Plenum Press, New York.

Lowry, O.H., Rosebrough, N.J., Farr, A.L. \& Randall, R.J. (1951) Protein measurement with the Folin phenol reagent. J. biol. Chem. 193, 265-275.

Menendez-Pelaez, A., Howes, K.A., Gonzalez-Brito, A. \& Reiter, R.J. (1987a) N-acetyltransferase activity, hydroxyindole-O-methyltransferase activity and melatonin levels in the Harderian glands of the female Syrian hamster: changes during the light:dark cycle and the effect 6-parachlorophenylalanine administration. Biochem. Biophys. Res. Commun. 145, $1231-1238$.

Menendez-Peleaz, A., Lopez, J. M., Alvarez-Uria, M., Howes, K.A. \& Reiter, R.J. (1987b) Cambios 
estructurales en la glandula Harderiana del hamster Syrio tras gonadectomia bilateral prolongada. Rev. Biol. Univ. Oviedo (in press).

Molnar, J., Arimura, A. \& Kastin, A.J. (1976) Presence of immunoreactive somatostatin in the salivary gland and saliva. Fedn Proc. Fedn Am. Socs exp. Biol. 35, 782, Abstr.

Moore, M.R., Thompson, G.G., Payne, A.P. \& McGadey, J. (1977) Cyclic oscillations in the activity of $\delta$ aminolevulinate synthetase and porphyrin synthesis in the Harderian gland during the estrous cycle of the golden hamster. Biochem. Soc. Trans. 5, 1475-1478.

Orsini, M.W. (1.961) The external vaginal phenomena characterizing the stages of the estrous cycle, pregnancy, pseudopregnancy, lactation, and the anestrous hamster Mesocricetus auratus Waterhouse. Proc. Anim. Care Panel 11, 193-206.

Patel, Y.C., Hoyte, K. \& Martin, J.B. (1979) Effect of anterior hypothalamic lesions on neurohypophysial and peripheral tissue concentration of somatostatin in the rat. Endocrinology 105, 712-715.

Polak, J., Pearse, A.G.E., Grimelius, L., Bloom, S. \& Arimura, A. (1975) Growth-hormone release- inhibiting hormone in gastrointestinal and pancreatic D cells. Lancet i, 1220-1222.

Reichlin, S. (1983) Somatostatin. N. Engl. J. Med. 309, 1495-1501 and 1556-1563.

Van Noorden, S., Polak, J.M. \& Pearse, A.G.E. (1977) Single cellular origin of somatostatin and calcitonin in the rat thyroid gland. Histochemistry 53, 243-247.

Vilchis, F., Hernandez, A., Perez, A.E. \& Perez-Palacios, G. (1987) Hormone regulation of the rodent Harderian gland: binding properties of androgen receptor in the male golden hamster. $J$. Endocr. 112, 3-8.

Webb, S.M., Champney, T.H., Steger, R.W., Bartke, A. \& Reiter, R.J. (1984) Immunoreactive somatostatin in the pineal gland of different species: circadian rhythm, effect of superior cervical ganglionectomy, pineal indole administration and lighting conditions, Biomed. Res. 5, 473-480.

Webb, S.M., Wass, J.A.H., Penman, E., Murphy, M., Serrano, J., Binimelis, J. \& Pavia, C. (1985) Circulating immunoreactive somatostatin in man. Effect of age, pregnancy, growth hormone deficiency and achlorhydria. Acta endocr., Copenh. 110, 145-151.

Received 11 August 1987 